\title{
Discussion on Legal Protection of Consumer Rights in Electronic Commerce Research
}

\author{
Yuting Gan \\ North China Electric Power University (Baoding), Baoding 071003, China \\ 1106805377@qq.com
}

Keywords: Legal protection; Consumer rights; Electronic commerce.

\begin{abstract}
E-commerce plays an increasingly important role in our lives, but it also faces many problems. How to standardize the electronic commerce, the protection of consumer rights in electronic commerce has become an urgent need to address the problem.Consumer protection for electronic commerce, the author will present problems and problems of e-commerce consumer protection reasons, from a legal perspective the coping strategy of e-commerce consumer protection.
\end{abstract}

\section{Introduction}

Along with the social economy and development of science and technology, e-commerce has been widely known to, and accepted by consumers, which have been developing rapidly. Rapid development but at the same time, e-commerce has brought new challenges, resulting in a new legal issue.Due to the virtual, e-commerce transactions and complaint difficult, serious asymmetries of information between operators and consumers and other reasons, violation of consumer rights in electronic commerce, and consumer rights and more tough.

\section{Problems of e-commerce consumer protection}

\subsection{Consumers ' rights were not guaranteed}

Amended in 2013, the eighth of the consumer rights protection law clearly states that: consumers aware of their purchase or use of goods or receiving services from the real situation right.Consumers have the right to according to the different product or service, require the operator to provide commodity price, place of origin, producer, usage, performance, specifications, grades, ingredients, production date, expiry date, inspection certificates, use instructions, service, or the contents, specifications, costs and other conditions of service.

In real life, however some operators intentionally product information, consumer fraud, and even production and sales of fake and shoddy products.In real life, however some operators intentionally product information, consumer fraud, and even production and sales of fake and shoddy products. When shopping online, consumers ' right to information cannot be guaranteed, In the traditional trade, consumers through direct contact with the product to know prices of goods, country of origin, producer, usage, performance, size, grade, main ingredients, production date, expiry date, inspection certificates, use instructions, service, or the contents, specifications, costs and other conditions of service, so as to decide whether to buy goods.

In contrast, online trading is virtualization, in the process, the nature of the goods is by remote understanding is not going to be real encounters merchandise, so there are many consumer goods but disappointed, not what your looking for merchandise. But if the buyer has to sign for commodities, commodity prices were too low, or businesses not purchase shipping insurance, this will make the buyers afraid to return because of the cost. Contrary to trade the principle of good faith, not in accordance with fundamental principles of market regulation.

To that end, gives the consumer the right to information is particularly necessary. The right of consumers, consumer buying and using goods or services a basic right, relating to consumer safety, to choose whether the final realization of the right. 
In the process of buying and using goods or services as long as they are with the correct judgment, selection, use, which are directly associated with the information, the consumer has the right to know, the operator should be provided.

\subsection{Personal privacy protection}

Everyone uses e-commerce transactions, consumers ' home address, telephone number, account numbers, passwords and other information are easily stolen because the network is not secure. A large number of criminals who use illegal software, viruses, Trojans and other stolen consumer privacy information, serious violation of consumer privacy.Legal protection of our country in terms of online privacy and e-commerce development needs not in proportion, it has also led to some consumers because of the easier to abuse the right to privacy, boycott, or to give up the use of electronic commerce, which hamper the further development of e-commerce [1].

\subsection{Transaction security}

E-commerce is mainly payment network, once the consumer online banking, PayPal account and password is compromised, it will naturally led to estimated losses to consumers.Consumers throughout the network transaction process will be monitored by Internet trading platform operators, but this kind of regulatory supervision, which discovered the problem and implementation of regulatory policy, or regular supervision and spot checks, criminals always abused to carry out unlawful acts [2]. E-commerce service providers also try to prevention by means of increased supervision, but the results are unsatisfactory.

\section{E-commerce consumer protection problems causes}

\subsection{E-commerce transaction management specifications}

Profits attract all types of people in the e-commerce market participation and market admittance system was not very strict, so transactions in e-commerce market will appear on various operators of varying quality. Consumers shopping depends to a large extent, on the protection of the interests of operators of e-commerce transactions, if strict compliance with the code of business ethics and the law, e-commerce transactions operators and consumers will be able to achieve a State of harmony between [3]. In e-commerce transactions because the operator more and in a State of relative dispersion, so trading platform to manage these operators conduct appears is in big trouble. Consumer rights not guaranteed is the main cause of the operator management was flawed. Lack of strict and detailed rules and regulations of electronic commerce transactions, lack of performance specification file, so make the inefficiency of consumer protection work.

\subsection{E-business operator supervision is inadequate}

In the traditional commercial activities and commercial activities between people subject to the restriction and control of the various social forces. First of all, the operator needs to check by the Department of business administration and management, quality of goods may be subject to inspection at any time, once the operators who sell substandard products will be consumer complaints after the sale, and as a result the operating store address fixed around consumers ' mistrust of the operators, thus affecting the operator's business. And in e-commerce business in the, because main of trading places is exists $\mathrm{Yu}$ network environment in the, so consumers and operators Zhijian completely is strange of relationship, both Zhijian exists with huge of gap, while in operators made has against consumers lawful rights and interests of of things Shi, General no corresponding of power to restricted operators in next of consumption behavior in the whether can comply with related of legal and commercial ethics [4].

\section{Improve our existing consumer protection legal system}

In China, the consumer rights protection law for the protection of consumer rights in electronic commerce provides the basic legal rules, but there are still shortcomings, can not fully adapt to the rapid development of electronic commerce. Therefore, legislation to further improve and expand the scope of consumer rights. 


\subsection{Improve the e-commerce field of consumer rights 4.1.1 Further improve the consumers' right}

In the field of e-commerce as consumers through remote communication with the operator of a data message based exclusively on information provided by the operator to select and judge, therefore, the consumer's right to know is more important, the consumer rights protection law should be based on the original expansion and extension. In the area of electronic commerce, the operators have obligations to provide information to consumers '. Should be detailed in the legislation of the right to regulate consumers ' scope, boundaries, operator fined penalties for violations of the consumer.

\subsubsection{To further improve consumer privacy protection}

Privacy refers to the natural person's private life and personal information secret is protected by law, without unlawful interference by others, it knows, collection, use, and disclosure of a personal right, and the extent to which the rights of others can step in his personal life, for your privacy to others public and people has the right to decide the scope and extent of the public. Privacy is a basic human right. Laws to protect consumer privacy in e-commerce occupy an important position, one may sometimes find themselves in after you bought the product you need, always find unknown phone texting to yourself, perhaps giving yourself browsing other sites also featured ad will pop up, which seriously violated consumers ' privacy rights. The consumer protection act to be regulated, to further protect consumer privacy.

\subsubsection{To further improve the safety of consumers, fair trade}

Article tenth of the consumer protection law of consumer rights to fair trade, namely, quality, pricing, metering and other fair trade conditions. When conducting e-commerce transactions, unable to free the shopping space changes and special used fraudulent price or conceal the true quality of goods and services. Consumers in e-commerce only according the on-line product information to determine whether the price is appropriate. In e-commerce field, consumers of fair trade right and cannot get is good of guarantees, consumers cannot rates understand commodity of nature, for some special commodity, as cosmetics, consumers cannot like in entity shop as can trial, this on will led to consumers cannot understand commodity of property, dang consumers using once after may for allergy wants to return, however then operators will to consumers has using and refused to accept return, so in e-commerce in the, consumers fair trade right and cannot according to Consumer protection law are guaranteed, lawmakers should be practical, situation appears in the e-commerce legislation the scope of circumventing the law lag. Secure transaction refers to the main e-commerce transaction payment network, once the consumer online banking, PayPal account and password is compromised, it will naturally led to estimated losses to consumers. In such situations, consumers throughout the network transaction process will be monitored by Internet trading platform operators, but this kind of regulatory supervision, which discovered the problem and implementation of regulatory policy, or regular supervision and spot checks, the results are unsatisfactory. Our legislators should on the one hand, through State.

\subsection{Establish and improve the market access system in e-commerce, qualification system}

On the premise of encouraging the development of e-commerce, in the form of legislation regulating e-commerce behavior, clearly e-commerce websites, such as market access, market management, composition, make e-commerce websites have "operational qualification", consistent with the protection of consumers ' Rights Act complaint in conditions. It also should clear the regulatory status of administrative organ for industry and Commerce electronic commerce to ensure that the final realization of the legitimate rights and interests of consumers [5]. Lack of strict and detailed rules and regulations for electronic commerce transactions, lack of performance specification file, legislators can formulate a series of laws and regulations, standardizing file to manage areas of e-commerce transactions, the traditional distinction between legal system and legal system in the field of electronic commerce.

\subsection{Efforts to strengthen the supervision}

In the area of electronic commerce, consumers often buy fakes on the Internet, leading to consumer rights have been violated, so as the regulating departments should strengthen supervision is not only 
supervision, proactive regulation and supervision should be strengthened. Commodity production, management, sales monitoring into a series of links. While strictly supervise the purchase means made way for commodities trader shall expose to consumers so that consumers see, understand, and protect consumers ' rights. Crack down on selling fake operators increase disciplinary measures, for selling fake personal and substantial property losses to consumers, operators, revoked business licenses, prohibiting once again engaged in online business.

\section{Conclusion}

E-commerce in China has more and more consumers around the world know and accept, so rules regulating the operation of e-commerce is very important, for our series of issues arising in e-commerce, we should combine our country of legal norms for the protection of consumers ' rights and interests. First of all improve the consumers ' rights in the field of electronic commerce should further improve the safety and security of consumers rights, right to information, the right to fair trade rights such as privacy protection, secondly to establish and improve the market access system in e-commerce, certification system and, finally, should strengthen supervision of the operators, so as to safeguard consumers ' rights and interests in the field of electronic commerce.

\section{References}

[1] Wang Ling. On perfecting the legal protection of consumer rights in electronic commerce [j]. The rule of law and society, 2009 (5): 8.

[2] tanyiping. On legal problem of consumer rights and interests protection in electronic commerce [j]. The rule of law and society, 2014 (12): 6.

[3] Liu Ying. Construction law consumer rights and interests protection in e-commerce system [j]. Economic and legal system, 2011 (10): 5.

[4] Ma Mingyue. Study on the legal aspects of consumer rights and interests protection in e-commerce transactions [j]. The rule of law and society, 2014 (9): 14.

[5] Fan Xiaoyu. Several problems of consumer rights and interests protection in electronic commerce [j]. Journal of Lanzhou University (Social Science Edition), 2009 (4): 16. " 